\title{
COVID-19 en Colombia e inmunidad de rebaño: ¿es momento de considerarla?
}

\author{
Doctor \\ Enrique Ardila \\ Editor \\ Revista Colombiana de Endocrinología, Diabetes y Metabolismo
}

\section{Antecedentes}

En diciembre de 2019, en Wuhan (Hubei, China) se reportaron 27 personas con neumonía de etiología desconocida; en enero de 2020 se identificó como agente a un virus zoonótico de la familia Coronaviridae (SARS-CoV-2). A su vez, la enfermedad producida por SARS-CoV-2 se denominó COVID-19; el virus se transmite de persona a persona por gotitas respiratorias, contacto directo o fómites. La COVID-19 tiene un período de incubación de 0-24 días. Algunos individuos no desarrollan síntomas y la mayoría se recupera, sin tratamiento específico. La COVID-19 se definió como pandemia en marzo de 2020 (13). Los efectos de la COVID-19 sobre el sistema endocrino aún no están bien establecidos; sin embargo, los individuos con diabetes mellitus (DM) que sufren COVID-19 tienen una mayor tasa de letalidad (entre el 10\% y el 11\%), lo cual establece que la DM es un factor de riesgo para desenlaces fatales entre aquellos que padecen COVID-19, algo similar a lo que se ha presentado por otras infecciones por coronavirus, como el síndrome respiratorio agudo grave (SARS) y el síndrome respiratorio de Oriente Medio (MERS-CoV). En un modelo en ratones transgénicos, se encontró que la célula del alvéolo pulmonar expresa el receptor de la dipeptidil peptidasa IV (DPP-IV). Por su parte, el MERS-CoV se une a dicho receptor; por lo tanto, se ha hipotetizado (a partir de dicho modelo) que la expresión del receptor de DPP-IV en la célula del alvéolo pulmonar podría estar involucrada en la asociación entre DM y un compromiso pulmonar inflamatorio más grave y prolongado en aquellos infectados por COVID-19 (1-4).

\section{Inmunidad de rebaño (IR), conceptos básicos}

\section{Número reproductivo básico (R0)}

El número reproductivo básico (R0) proporciona información sobre la velocidad y la dinámica en la cual una enfermedad puede propagarse poblacionalmente, de modo que un valor umbral de 1,0 indica cuándo ocurrirá un brote. Si R0 >1,0, entonces, es una epidemia; si R0 =1,0, es endemia; y si es $<1,0$, existiría control de la enfermedad. No se dispone aún del R0 para COVID-19 en Colombia, aunque este podría estar entre 2,0 y 3,0. El R0 posee tres componentes, a saber: (b): la tasa de ataque (para COVID-19 se estima entre 60\%-80\%); (c): número de contactos potencialmente infecciosos de un caso (no hay datos en nuestro medio, pero extrapolando datos de población europea, podría ser de 30 contactos/semanales); (d): duración de la transmisibilidad (actualmente se considera que para infectados asintomáticos es de 14 días [2 semanas]; para sintomáticos leves, de 21 días [3 semanas]; y para sintomáticos graves o críticos, de 28 a 36 días [4 semanas]). La fórmula para R0 es: R0 = b × c × d (5-7). Si planteamos para Colombia un (b) del 60\%, con un (c) de 30 y un (d) de 2 semanas, el R0 sería: R0: 0,6 × $30 \times 2=36$ (cada caso de COVID-19 produciría 36 casos/semana). Para un (b) del $80 \%$, un (c) de 20 y un (d) de 4 semanas, el R0 = 0,8 $\times 20 \times 4=64$ (cada caso de COVID-19 produciría 64 casos/semana). Para un (b) del 30\%, un (c) de $10 \mathrm{y}$ un (d) de 2 , el R0 = 0,3 $\times 10 \times 2=6$. Para un (b) del 10\%, un (c) de 10 y un (c) de 3 , el R0 $=0,1 \times 10 \times 3=3$. Para un (b) del $10 \%$ un (c) de 5 y un (d) de 2 , el R0 $=0,1 \times 5 \times 2=1$.

\section{IR y proporción crítica de vacunados (Pc)}

La IR es una situación en la que suficientes individuos de una población adquieren inmunidad contra una infección (por vacunación o por haber tenido la enfermedad). Esto es, cuando hay un brote, al aumentar el número de individuos inmunes, disminuye la probabilidad de contacto entre uno susceptible y uno infectado (hasta que llega el momento en el que se bloquea la transmisión) La Pc junto con el R0 son los indicadores de la IR; la Pc identifica el "umbral" que debe alcanzar la cobertura de vacunación para controlar o erradicar un patógeno (7-9). Para que la IR bloquee la transmisión, la inmunización debe lograr un valor de R0 <1,0; para esto, la Pc debe ser: Pc = 1 - (1/R0). Por ejemplo, para la COVID-19, en un R0 de 2 (si existiese una vacuna con efectividad demostrada), la Pc sería: 1 - (1/2,0) = 0,5 (50\%); lo que indicaría que habría que vacunar al 50\% de la población para bloquear la transmisión. 


\section{¿Existe otra forma de aplicar la IR como concepto poblacional?}

Otra forma de aplicar la IR es esperar a que se presente un número suficiente de personas infectadas, por ejemplo, en una población en donde no se generen medidas de aislamiento, distanciamiento, cuarentena, entre otras. Si la COVID-19 continúa propagándose al ritmo actual, una proporción importante de individuos se infectará, y entre aquellos que sobrevivan, se desarrollará inmunidad, lo que haría que el brote desapareciera por sí mismo (porque el virus tendría cada vez más dificultades en encontrar un huésped susceptible). El valor estimado poblacional para IR (para COVID-19) es del 60\%. Esto plantea que se frenaría la propagación y se desarrollaría una IR de manera "controlada". Sin embargo, un número importante de individuos se infectarían en un corto período, lo que haría que el pico del brote tuviera mayor magnitud y menor duración (pero con mayor número de desenlaces fatales y mayor necesidad de atención intrahospitalaria), lo cual colapsaría el sistema de salud (10-12). Asimismo, si se disminuye la velocidad de propagación (aplanamiento de la curva [Figuras 1A y 1B]), probablemente la estabilidad del sistema de salud sería más viable y habría mejor capacidad de respuesta en términos de atención.
La clave está en que el R0 es cambiante a lo largo del brote (a mayor R0, mayor magnitud y menor duración tendrá el brote, y viceversa). Lo anterior indica que, para un (b) y (d) constantes, la única opción de reducir el R0 es a través de la disminución de (c) (por medio de la instauración de medidas de salud pública [farmacológicas y no farmacológicas]). Por lo anterior, a partir del hecho de que no disponemos aún de una vacuna accesible, así como tampoco de antivirales o medicamentos que prevengan o modifiquen significativamente los desenlaces en la COVID-19; y bajo un escenario hipotético, en donde se genere una inmunidad completa y permanente hacia el SARS-CoV-2 en individuos que padecen o hayan padecido la COVID-19, cabe preguntarnos: ¿seguimos insistiendo en las intervenciones poblacionales de aislamiento, distanciamiento, cuarentena, entre otras, en nuestra sociedad, donde cerca del $50 \%$ vive de la economía informal, en donde las consecuencias económicas serán de gran magnitud? ¿Quién o quiénes asumirán el costo del aislamiento y distanciamiento social? ¿0 es momento de plantear la IR como estrategia para enfrentar esta situación (protegiendo a la población de mayor edad y a aquellos con comorbilidades y mayor vulnerabilidad) y volver a nuestras actividades de la vida cotidiana lo más rápido posible?

Solo el tiempo dirá qué fue lo mejor.

Figura 1. A. Efectos que podrían originarse sobre la curva epidémica en una pandemia por intervenciones como el aislamiento, el distanciamiento social, la cuarentena, entre otras.

Ralentización en el número de casos

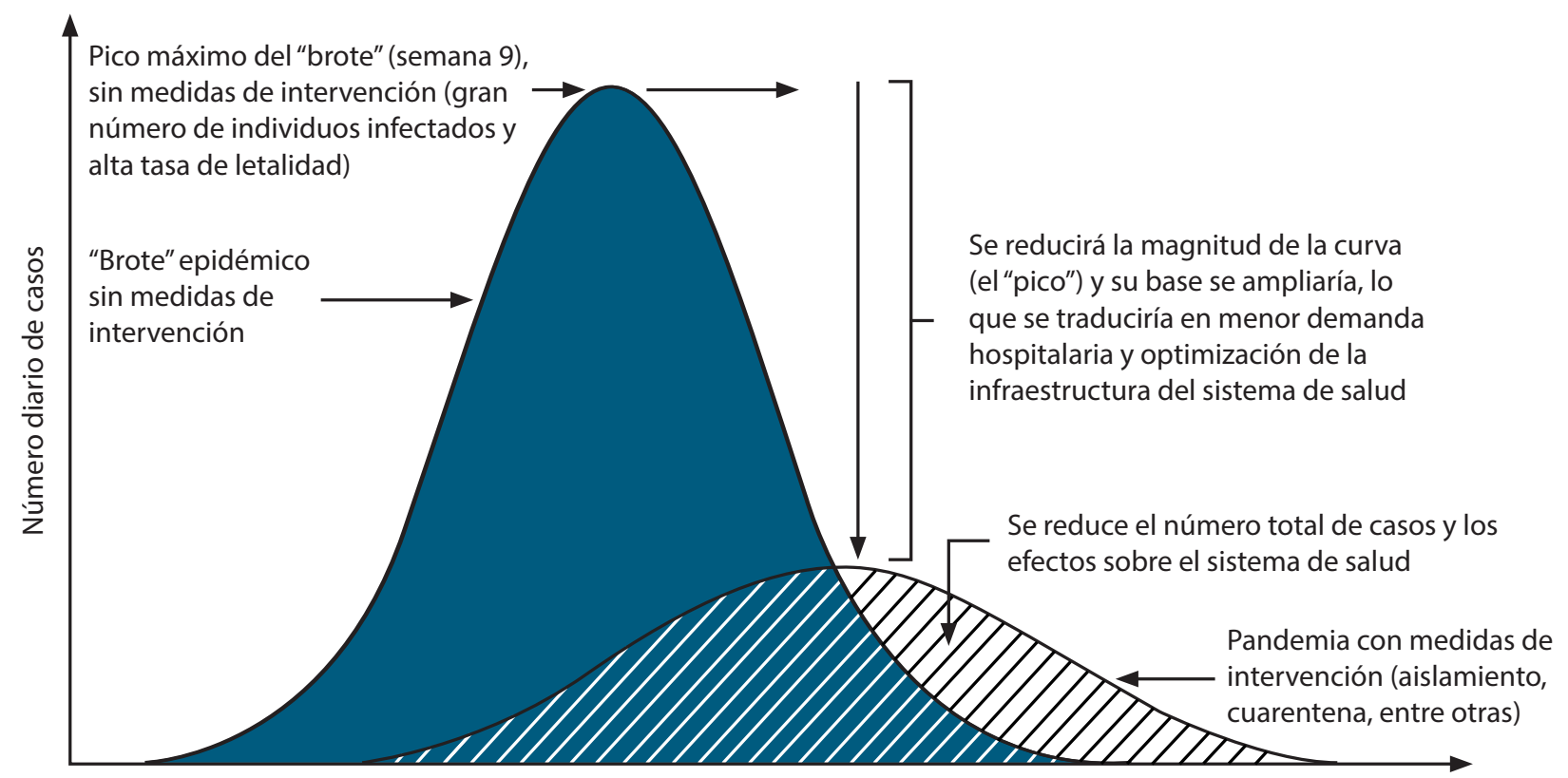

Número de días a partir del primer caso 
Figura 1. B. Efectos del R0 sobre las curvas epidémicas. A un mayor valor del R0, la curva gana en magnitud y se reduce en tiempo, lo cual lleva a un mayor número de individuos afectados en una menor cantidad de tiempo, aspecto que se acompañaría de un mayor número de desenlaces fatales. Véase el texto para más detalles. Fuente: archivo del autor.

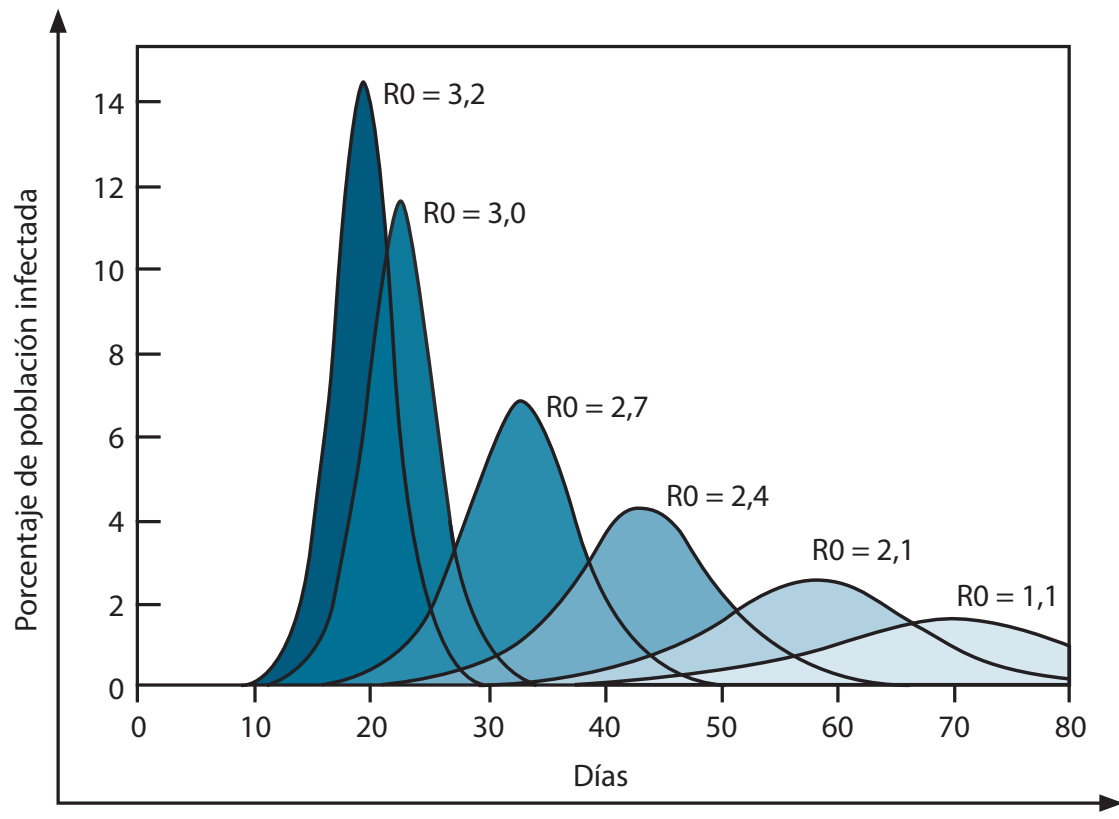

Atentamente,

Hernando Vargas-Uricoechea Médico Especialista en Medicina Interna y Endocrinología. MSc en Epidemiología. Doctor en Ciencias de la Salud. Ph.Dc en Ciencias Biomédicas.

Profesor asociado y director del Grupo de Investigación en Enfermedades Metabólicas, Departamento de Medicina Interna, Universidad del Cauca, Colombia. Miembro de número, Asociación Colombiana de Endocrinología, Diabetes y Metabolismo.

\section{Referencias}

1. Wu F, Zhao S, Yu B, Chen YM, Wang W. A new coronavirus associated with human respiratory disease in China. Nature. 2020;579(7798):265-9.

2. Zhu N, Zhang D, Wang W, Li X, Yang B. A Novel Coronavirus from Patients with Pneumonia in China, 2019. N Engl J Med. 2020;382(8):727-33.

3. Zhang C, Huang S, Zheng F, Dai Y. Controversial treatments: an updated understanding of the Coronavirus Disease 2019. J Med Virol. 2020. doi: 10.1002/ jmv.25788

4. Kulcsar KA, Coleman CM, Beck SE, Frieman MB. Comorbid diabetes results in immune dysregulation and enhanced disease severity following MERS-CoV infection. JCI Insight. 2019; 4:131774.

5. Lloyd AL, Kitron U, Perkins TA, Vazquez-Prokopec GM, Waller LA. The basic reproductive number for disease systems with multiple coupled heterogeneities. Math Biosci. 2020;321:108294.

6. Viceconte G, Petrosillo N. COVID-19 R0: Magic number or conundrum? Infect Dis Rep. 2020;12(1):8516.
7. Peeples L. Rethinking herd immunity. Nat Med. 2019;25(8):1178-80.

8. Wallinga, J, Lipsitch M. How generation intervals shape the relationship between growth rates and reproductive numbers. Proc Biol Sci. 2007;274:599604.

9. Anderson RM, May RM. Infectious Diseases of Humans: Dynamics and Control. Oxford, UK: Oxford Science Publications; 1992.

10. Brett T, Ajelli M, Liu QH, Krauland MG, Grefenstette JJ. Detecting critical slowing down in high-dimensional epidemiological systems. PLoS Comput Biol 2020;16(3):e1007679.

11. Dudley MZ, Privor-Dumm L, Dubé È, MacDonald NE. Words matter: Vaccine hesitancy, vaccine demand, vaccine confidence, herd immunity and mandatory vaccination. Vaccine. 2020;38(4):709-11.

12. Kwok KO, Lai F, Wei WI, Wong SYS, Tang J. Herd Immunity - Estimating the Level Required to Halt the COVID-19 Epidemics in Affected Countries. J Infect. 2020. pii: S0163-4453(20)30154-7. 